\title{
Critical Illness and the Aging Population: Clinical Implications and Pharmacotherapy Challenges
}

\author{
Catherine K. Floroff ${ }^{1}$, Patricia W. Slattum ${ }^{2}$ and Gretchen M. Brophy ${ }^{3^{*}}$ \\ ${ }^{1}$ Medical University of South Carolina, South Carolina College of Pharmacy, 280 Calhoun Street, MSC 132, Charleston, SC, USA \\ ${ }^{2}$ Department of Pharmacotherapy and Outcomes Science, Virginia Commonwealth University, Richmond, VA, USA \\ ${ }^{3}$ Department of Pharmacotherapy and Outcomes Science and Neurosurgery, Virginia Commonwealth University, Richmond, VA, USA
}

"Corresponding author: Gretchen M Brophy, Professor of Pharmacotherapy and Outcomes Science and Neurosurgery, Virginia Commonwealth University, 410 N. 12 th Street, Room 642, Richmond, VA, USA, Tel: (804) 828-1201; Fax: (804) 828-0343; E-mail: gbrophy@vcu.edu

Rec date: Dec 09, 2014; Acc date: Dec 16, 2014; Pub date: Dec 18, 2014

Copyright: $\odot 2015$ Gretchen M, et al. This is an open-access article distributed under the terms of the Creative Commons Attribution License, which permits unrestricted use, distribution, and reproduction in any medium, provided the original author and source are credited.

\begin{abstract}
The rate of critically ill older patients being admitted to intensive care units (ICU) continues to rise. Multiple factors influence the complexity of treatment strategies and create challenges for optimizing patient care while avoiding unwanted adverse effects. These factors include Pharmacokinetic (PK) and Pharmacodynamics (PD) changes that are compounded by both age and critical illnesses and may heighten the risk of suboptimal treatment strategies and adverse drug events, including neurotoxicity, to the patient. Medications that increase the risk for adverse drug events, drug-drug interactions, and drug-disease interactions may be classified as a potentially inappropriate medications based on risk versus benefit of use in older adults. However, many times these agents are needed for treatment of critically ill patients and must be dosed and monitored appropriately to avoid complications, such as delirium, which is associated with increased morbidity and mortality in the older population. Unfortunately, clinical pharmacotherapy and outcome studies with extreme age considerations for pharmacotherapy are lacking. This article reviews the pharmacotherapy challenges in older critically ill patients, and provides medication considerations for avoiding adverse drug events that may complicate patient care.
\end{abstract}

Keywords: Aging; Elderly; Older adult; Critically ill; Delirium: Pharmacotherapy; Pharmacokinetic; Pharmacodynamics; Adverse effects; Potentially inappropriate Medications

\section{Abbreviations: \\ ADEs: Adverse Drug Events; cIV: Continuous Infusion; CO: Cardiac Output; GFR: Glomerular Filtration Rate; GI: Gastrointestinal; ICU: Intensive Care Unit; PaCO2: Partial pressure of Carbon dioxide; PD: Pharmacodynamic; PIM: Potentially Inappropriate Medication; RASS: Richmond Agitation Sedation Scale; RRT: Renal Replacement Therapy; Vd: Volume of Distribution}

\section{Introduction}

Older adults, 65 years or older, currently account for about half of all intensive care unit (ICU) admissions [1]. By 2030, 70 million people in the United States will be over the age of 65 and will account for $20 \%$ of the population [1]. The "oldest-old", adults aged 85 years and older, are the most rapidly growing age group [2]. Compared with younger adults, older individuals have more comorbid conditions, such as malnutrition and cognitive or functional impairment, and are expected to have a higher medication burden [3,4]. For example, almost half of all older adults receive a potentially inappropriate medication (PIM) during their surgical hospitalization [5]. Increased medication use leads to an increased incidence of medication-related problems and delirium [3]. In addition, disease severity increases the complexity of treating older adults with multiple comorbid risk factors in the ICU and may predict poor outcomes.
Disease-state specific guidelines and protocols often do not take advanced age into consideration when providing recommendations. One reason for exclusion may be because clinical trials are not likely to include patients based on extreme age, especially those over 80 years of age [6]. In fact, only $5 \%$ of trials are designed specifically for adults aged 65 years and older [7]. Other major factors that may lead to exclusion and are characteristics in this patient population include comorbid conditions and the use of concomitant medications [4]. This can make pharmacotherapy decision-making problematic because age and complications encountered during critical illness weigh heavily on medication therapy management. Treatment options may differ for geriatric patients who are "young-old", with physiology similar to a mature adult, and those who are the "oldest-old" experiencing advanced functional impairments, frailty and chronic illness. Underrepresentation of older adults in clinical trials and subsequent guideline development makes it more difficult for clinicians to make evidence-based pharmacotherapy recommendations.

This review addresses pharmacotherapeutic challenges and clinical implications in critically ill older adults, with a focus on underlying pharmacodynamics (PD) and pharmacokinetic (PK) changes that can impact pharmacotherapy dosing and monitoring recommendations in an older ICU patient population.

\section{Pharmacotherapy Challenges in the Older ICU Patient}

Pharmacotherapy of critically ill older adults is multifaceted due to considerations such as co-morbidities, severity of illness, preadmission cognitive and functional status, and $\mathrm{PK} / \mathrm{PD}$ variations in these patients. ICU-related factors that may further complicate treatment strategies include exposure to high risk medications (e.g., narcotics, 
sedatives, hypnotics, nephrotoxins, vasopressors) and invasive medical devices, such as mechanical ventilation or mechanical assist devices. Older patients, particularly those aged greater than 80 years, are more sensitive to certain medications used during critical illness, such as anesthetic drugs, than younger patients [8]. Multiple-drug regimens and the potential for significant drug-drug or drug-disease state interactions also must be considered when making clinical decisions in older patients admitted to the ICU with an extensive medication history. Furthermore, clinical judgment must be used when considering ICU discharge, as certain medications started in the ICU, such as stress ulcer prophylaxis (SUP), are often continued during post-ICU transitions of care without an appropriate indication and can cause further complications in older adult patients [9].

Multiple evidence-based approaches have been developed to examine PIM use in older adults [10-14]. Medications that increase the risk for adverse drug events (ADEs), drug-drug interactions, and drugdisease interactions may be classified as a PIM based on risk versus benefit of use in older adults aged 65 years and older [10]. Total number of PIMs in 120 older adults 60 years and older increased from 159 on preadmission to 253 upon discharge from medical surgical ICUs [15]. Common PIMs used in the ICUs include certain opioids, benzodiazepines, anticholinergics, and barbiturates. Other medications used in the critical care setting, including inhaled and intravenous anesthetics as well as neuromuscular blocking agents, should be initiated with caution due to alterations in PK and PD in these patients.

Delirium, which is a potential consequence of PIM use, is associated with increased morbidity and mortality as well as increased length of stay and healthcare costs in the older population [16-18]. Additionally, recognition of preexisting cognitive impairment in older patients by ICU attending physicians and intern physicians is poor [19]. One study found that haloperidol for delirium was administered more frequently to patients 65 years and older compared to younger patients in the ICU. Furthermore, the older cohort may have received more aggressive treatment for agitation which resulted in higher doses of sedatives [20]. Few studies have specifically evaluated the occurrence, duration and factors contributing to delirium in critically ill older patients, especially those with acute neurological injury.

\section{Pharmacokinetic Changes and Recommendations}

While the etiology of delirium and other ICU-related complications is believed to be multifactorial, pharmacotherapy considerations require a clear understanding of the PK principles and how $\mathrm{PK}$ can be altered in the elderly with a critical illness. Table 1 lists potentially combined effects of PK changes and advanced age in critically ill older adults. Understanding PK changes in older adults may be helpful when considering treatment regimens in the ICU.

\begin{tabular}{|c|c|c|c|c|}
\hline $\begin{array}{l}\text { PK Parameter } \\
\text { Effected }\end{array}$ & $\begin{array}{l}\text { Physiologic Changes in Older } \\
\text { Adults }\end{array}$ & $\begin{array}{l}\text { Potential Physiologic Changes in } \\
\text { Critical Illness }\end{array}$ & $\begin{array}{l}\text { Potential Combined Effect in } \\
\text { Critically III Older Patients }\end{array}$ & $\begin{array}{l}\text { Examples of Medications } \\
\text { Impacted by PK Changes in } \\
\text { Critically III Elderly Patients }\end{array}$ \\
\hline Absorption & $\begin{array}{l}\uparrow \text { Gastric pH } \\
\downarrow \text { Gastric motility } \\
\downarrow \text { Absorptive surface } \\
\downarrow \text { Splanchnic blood flow }\end{array}$ & $\begin{array}{l}\uparrow \text { Gastric pH } \\
\downarrow \text { Gastric motility } \\
\downarrow \text { Perfusion } \\
\text { Enteral nutrition Exocrine pancreatic } \\
\text { dysfunction }\end{array}$ & $\begin{array}{l}\uparrow \downarrow \text { Drug absorption with GI changes } \\
\text { (pKa of drug) } \\
\downarrow \text { Drug and nutrient absorption with } \\
\text { decreased perfusion } \\
\downarrow \text { Bioavailability of oral drugs }\end{array}$ & $\begin{array}{l}\text { Itraconazole, ketoconazole, } \\
\text { sulfonamides, dapsone, } \\
\text { acetaminophen, dabigatran }\end{array}$ \\
\hline Distribution & $\begin{array}{l}\downarrow \text { CO } \\
\downarrow \text { Total body water } \\
\downarrow \text { Lean body mass } \\
\downarrow \text { Serum albumin } \\
\uparrow \text { Alpha- } 1 \text { acid glycoprotein } \\
\downarrow \text { Body fat, but } \uparrow \% \text { of } \\
\text { total body weight }\end{array}$ & $\begin{array}{l}\downarrow \mathrm{CO} \\
\uparrow \text { total body weight and total body } \\
\text { water (fluid accumulation/ volume } \\
\text { overload) } \\
\downarrow \text { Lean body mass } \\
\downarrow \text { Serum albumin } \\
\uparrow \text { Alpha-1acid glycoprotein } \\
\uparrow \downarrow \text { Plasma pH }\end{array}$ & $\begin{array}{l}\text { Third spacing and Vd alterations } \\
\text { Significant changes in unbound } \\
\text { fraction of drugs - changes in effect } \\
\text { and rate of elimination }\end{array}$ & $\begin{array}{l}\text { Aminoglycosides, } \quad \beta \text {-lactams, } \\
\text { daptomycin, phenytoin }\end{array}$ \\
\hline Metabolism & $\begin{array}{l}\downarrow \text { Hepatic mass } \\
\downarrow \text { Enzyme activity (primarily phase I } \\
\text { [oxidative pathways]) } \\
\downarrow \text { Hepatic blood flow }\end{array}$ & $\begin{array}{l}\downarrow \text { Enzyme activity(phase I reactions } \\
\text { are more profound than phase II } \\
\text { conjugative metabolism) } \\
\uparrow \downarrow \text { Hepatic blood flow (early vs late } \\
\text { effects based on disease state, } \\
\text { iatrogenic vasocontriction) }\end{array}$ & $\begin{array}{l}\text { Reduced first-pass metabolism } \\
\text { Reduced effect of CYP2D6 prodrug } \\
\text { substrates } \\
\begin{array}{l}\text { Decreased clearance of high } \\
\text { extraction drugs }\end{array}\end{array}$ & $\begin{array}{lr}\begin{array}{l}\text { Codeine, } \\
\text { hydrocodone, } \\
\text { clopidogrel, }\end{array} & \begin{array}{r}\text { oxycodone, } \\
\text { tramadol, } \\
\text { dabigatran, }\end{array} \\
\begin{array}{l}\text { Lidocaine, } \\
\text { propranolol, }\end{array} & \begin{array}{l}\text { verapamil, } \\
\text { labetalol, promethazine }\end{array}\end{array}$ \\
\hline Excretion & $\begin{array}{l}\downarrow \text { Renal blood flow } \\
\downarrow \text { GFR } \\
\downarrow \text { Tubular secretion } \\
\downarrow \text { Renal mass } \\
\downarrow \text { Ventilatory Capacity }\end{array}$ & $\begin{array}{l}\downarrow \text { GFR } \\
\text { RRT } \\
\downarrow \text { Ventilatory Capacity }\end{array}$ & $\begin{array}{l}\downarrow \text { Drug elimination and increased } \\
\text { risk of toxicity } \\
\downarrow \text { Elimination of inhaled anesthetic } \\
\text { agents }\end{array}$ & $\begin{array}{lr}\text { Isoflurane, } & \text { desflurane, } \\
\text { sevoflurane, } & \text { H2RAs, } \\
\text { enoxaparin, } & \text { antibiotics, } \\
\text { antiepileptics, fluroquinolones }\end{array}$ \\
\hline
\end{tabular}

Table 1: Combined Effects of Pharmacokinetic Characteristics in Critically Ill Older Patients [21-24]. 


\section{Absorption}

The gastrointestinal tract (GI) has a large functional reserve capacity in healthy older patients. However, gastric acid secretion is reduced in healthy older adults, due to atrophic changes in gastric mucosa [21]. Hypoperfusion and decreased motility observed during critical illness, in addition to reduced gastric acid secretion, may cause significant GI absorption abnormalities in older patients in the ICU [21-22]. Critically ill patients are often prescribed acid suppressing medications (eg, histamine-2 receptor antagonists [H2RAs], proton pump inhibitors [PPIs]) for GI prophylaxis which will raise the stomach $\mathrm{pH}$ further and introduce the possibility of increased drugdrug interactions as well as side effects such as agitation and infection [22]. Decreased GI perfusion may lead to complications such as slower onset of effect of oral medications or an extended time to maximum concentration. Lack of nutrition and opioids may considerably decrease GI motility which may also affect absorption. Drug-drug interactions may result if medications remain in the GI tract for an extended period of time. This is considerable in elderly patients as they are often taking considerably more medications than younger adults [3]. Critically ill patients who cannot take food by mouth often require feeding tubes and enteral nutrition which can also affect the absorption of medications. Enteral feedings are often inconsistent, due to frequency of rate changes and interruptions for procedures, leading to interactions and wide variation in plasma drug concentrations, particularly in patients with preexisting GI conditions and significant hypomotility. Reduced prothrombin time (PT), when warfarin is administered with enteral nutrition suggests the possibility of warfarin malabsorption due to binding to nutritional formula [22]. Other possible drug interactions with enteral nutrition include phenytoin, fluconazole, ciprofloxacin and levofloxacin [22].

Age-related changes in absorption can impact route of medication administration in the ICU. Decreased skin barrier, cutaneous circulation, and dermal thickness which are often present in older adults can introduce complications when establishing an intravenous administration route [23]. Additional caution should be taken when starting medications with a high extravasation risk, such as amiodarone, through peripheral lines in older patients with reduced skin thickness. Furthermore, the absorption rate of medications administered subcutaneously, such as enoxaparin and fondaparinux, used for deep vein thrombosis (DVT) prophylaxis may be decreased due to reduced tissue perfusion [24].

\section{Distribution}

Distribution is a significant PK consideration due to variable fluid shifts in hemodynamically unstable patients. Volume of distribution may be altered in elderly patients due to decreased lean body mass and total body water $[22,25]$. Reduced loading doses of lipophilic sedatives, such as diazepam and midazolam, may be warranted. Rapid changes in total body weight during critical illness must also be considered [25]. Third spacing results in increased volume of distribution for hydrophilic medications [25]. Net increases in body weight secondary to fluid resuscitation must be added to the total volume of distribution for hydrophilic drugs [25]. However, fluid shifts are variable as patients start to mobilize fluid which may result in smaller as well as larger than expected volumes of distribution. Hydrophilic medications with a narrow therapeutic window can lead to toxicity if dosages are not adjusted and monitored more frequently. Pulse dosing of certain parenteral antibiotics such as aminoglycosides, vancomycin, and colistimethate may be warranted.

Changes in protein binding are not clinically relevant in healthy older adults but should be considered during critical illness [26]. Albumin, which binds acidic drugs, is commonly reduced by $15-20 \%$ in acute illnesses such as renal dysfunction, hepatic disease, or trauma [21]. Levels of alpha1-acid glycoprotein increase slightly with age and this is more pronounced in older adults with acute stress and inflammatory conditions [26]. Hypoalbuminemia or altered glycoprotein levels can lead to higher levels of active free drug [22]. Medications that are highly protein bound, such as warfarin, digoxin, and aspirin, lead to the increased risk of toxicity. This can also change the effect and rate of elimination of certain medications. For example, low serum albumin in older adults can result in increased potency of hepatically cleared medications such as etomidate. Therefore, bolus doses of etomidate should be reduced by 30 to $50 \%$ in these patients [27]. Propofol displays a small initial volume of distribution, high protein binding, and hepatic metabolism. The half-life of propofol is prolonged in older individuals, especially those greater than 80 years old [8]. Literature has shown that critically ill older patients required a reduction in propofol infusion rate of $30 \%$ to $50 \%$ compared to younger patients to maintain the same anesthetic effect [8]. In general, propofol should be initiated at the lowest starting dose, perhaps 5 micrograms $/ \mathrm{kg} / \mathrm{min}$, and titrated to effect. Other examples of highly protein bound drugs used in the intensive care environment are diazepam, midazolam, phenytoin, and fentanyl.

\section{Metabolism}

Hepatic enzyme activity is reduced in older age and in critical illness [21-22]. Bioavailability of drugs that undergo extensive firstpass metabolism (e.g. metoprolol, labetalol, hydralazine) will increase. Reduced first-pass metabolism may also decrease the activation of prodrugs, such as enalapril, clopidogrel and dabigatran. Prodrug substrates of CYP2D6 (e.g. codeine, oxycodone, hydrocodone, tramadol) will exhibit a decreased effect and high extraction drugs (e.g. lidocaine, beta blockers, morphine, midazolam) will also show decreased clearance. Lorazepam, temazepam, and oxazepam undergo conjugation by glucuronidation, which remains intact despite hepatic failure. Extrahepatic sites of drug metabolism, such as the GI and respiratory tract, may become an important consideration in drug clearance when hepatic dysfunction is severe. Furthermore, drug-drug interactions become problematic due to polypharmacy in critically ill patients and may be further complicated by dose, narrow therapeutic index medications, and medications which display zero-order pharmacokinetics (eg, ethanol, phenytoin) [28]. Examples of drugdrug interactions commonly encountered in our critically ill older adults with neurological injury that alter pharmacokinetic characteristics, such as metabolism, are listed in Table 2.

Frailty, inflammation and delirium are confounding factors of drug metabolism. Frailty is multi-dimensional, due to the loss of physical and cognitive reserve, which leads to decreased ability to tolerate the stress of critical illness and increased vulnerability for adverse events [29]. Frailty is strongly correlated with age and probably increasing among critically ill patients [30]. This can lead to more difficulty in normalizing the critically ill older patient when attempting best sedation practices of daily interruption and early mobilization. 


\begin{tabular}{|l|l|l|l|}
\hline Object Drug & Precipitating drug & Mechanism of interaction & Potential consequence \\
\hline Midazolam & Omeprazole & $\begin{array}{l}\text { Slowed benzodiazepine metabolism and } \\
\text { clearance }\end{array}$ & $\begin{array}{l}\text { Over-sedation can increase time on ventilator } \\
\text { support and prolong ICU stay }\end{array}$ \\
\hline Midazolam & Phenytoin & Increased metabolism of midazolam & $\begin{array}{l}\text { Under-sedation can cause hyper-catabolism, } \\
\text { immunosuppression, } \\
\text { hypercoagulability, and increased sympathetic } \\
\text { activity }\end{array}$ \\
\hline Dexamethasone & Phenytoin & Increased metabolism of dexamethasone & $\begin{array}{l}\text { Postextubation upper airway complications and } \\
\text { need for reintubation }\end{array}$ \\
\hline Fentanyl & Fluconazole & Decreased clearance of fentanyl & $\begin{array}{l}\text { Risk may be greater for respiratory depression, } \\
\text { hypotension, and CNS toxicity }\end{array}$ \\
\hline Fluoxetine & Haloperidol & Inhibition of haloperidol metabolism & $\begin{array}{l}\text { Risk may be greater for arrhythmias, } \\
\text { anticholinergic effects, sedation, and EPS } \\
\text { symptoms }\end{array}$ \\
\hline Valproic acid & Phenytoin & $\begin{array}{l}\text { Displacement of phenytoin from binding } \\
\text { sites }\end{array}$ & $\begin{array}{l}\text { Risk may be greater for sedation, confusion states, } \\
\text { or cerebellar dysfunction }\end{array}$ \\
\hline
\end{tabular}

Table 2: Examples of Drug-Drug Interactions in Critically Ill Patients that Alter Pharmacokinetic Characteristics [28].

\section{Renal elimination}

Doses of certain renally eliminated medications should be adjusted with declining kidney function, especially in patients with acute kidney injury (AKI) or those undergoing dialysis. Age-associated functional kidney changes are listed in Table 3 . Patients that reach 80 years of age will likely have a glomerular filtration rate (GFR) less than $59 \mathrm{~mL} / \mathrm{min}$ due to decline of renal blood flow with reduced cardiac output [31]. Underlying chronic kidney disease (CKD) is a common comorbid condition. While there is substantial inter-individual variability, serum creatinine may not be a good indicator of renal function due to decreased production and elimination of creatinine in advanced age [21]. Furthermore, critically ill patients may have an altered serum creatinine due to factors other than GFR including increased muscle breakdown, trauma, protein catabolism, shock, contrast administration, surgery and immobility [32,33]. Clearance of medications that depend on hepatic or renal elimination pathways would be decreased by organ edema or failure. In critically ill elderly patients who are markedly catabolic or have large fluid shifts, the GFR should be measured via 24 hour urine collection instead of predicted by estimating creatinine clearance [32].

Variable kidney function may lead to toxicity and changes in dosing recommendations of medications with a narrow therapeutic range. This is especially troublesome in critically ill elderly patients with agerelated physiological changes (i.e. decrease muscle mass and difficulties estimating creatinine clearance) in addition to fluctuations in daily renal function during acute illness, making renal clearance estimates and drug dosing more challenging. Valproate and meropenem, with well-documented tolerability in adults and children with meningitis, can cause a significant pharmacokinetic interaction in older adults with renal impairment and decreased renal excretion of both drugs [34]. Valproate concentrations may decrease with an average of $66 \%$ within 24 hours and cause relapse of seizures in some patients [34]. Fluoroquinolones (e.g. levofloxacin) need to be renally adjusted in the setting of reduced creatinine clearance [35]. Older, critically ill patients, especially with neurological compromise, should be monitored carefully for increased central nervous system (CNS) effects that are often contributed to aging (e.g. confusion, weakness, tremor) [35]. Antibiotics that use dosing nomograms based on creatinine clearance, such as vancomycin and aminoglycosides, are commonly used in the ICU and must take these principles into consideration. Critically ill older patients are also prone to decreased elimination of opioids and benzodiazepines with renally eliminated metabolites which can lead to adverse effects, such as over sedation and decreased respiratory drive. Morphine and midazolam are classic examples that are commonly used in the ICU and are potentially problematic especially with repeated intermittent doses or administered as a continuous infusion [27]. Clinicians should consider alternatives, such as dexmedetomidine, an alpha-2 agonist that does not impact respiratory drive to the same extent for those patients requiring continuous intravenous infusions for sedation and may prevent delirium [36]. H2RAs are frequently prescribed for SUP in ventilated patients and lead to CNS adverse effects if the dose is not adjusted for renal impairment, especially in elderly and critically ill patients [37,38]. Drug accumulation with multiple doses of antiarrhythmics (e.g. amiodarone, carvedilol) may be more pronounced in renal and hepatic impairment and could be harmful in critically ill elderly patients if physiologic functional changes of aging are not considered [39]. As a general rule, renal function should always be considered when prescribing medications to older adults in the ICU and the initial dosing for intermittent (PRN) medications as well as continuous infusion rates should be low, titrated upward and include close monitoring.

\section{Pharmacodynamic Changes and Recommendations}

Relative to pharmacokinetic changes, very little is known about the PD differences in those aged greater than 85 years. Alterations in PD may result from changes in the concentrations of the drug at the receptor, drug-receptor interactions (variation in receptor number, receptor affinity, second messenger response, and cellular response), and homeostatic regulation. Table 3 shows organ-system specific PD changes effected in older adults and potentially combined effects in critically ill older adults. 


\begin{tabular}{|c|c|c|c|c|}
\hline $\begin{array}{l}\text { System affected via } \\
\text { PD changes }\end{array}$ & Physiologic Changes in Elderly & $\begin{array}{l}\text { Potential Physiologic Changes } \\
\text { in Critical Illness }\end{array}$ & $\begin{array}{l}\text { Potential Combined Effect } \\
\text { in Critically III Elderly } \\
\text { Patients }\end{array}$ & $\begin{array}{l}\text { Examples of Medications } \\
\text { Impacted by PD Changes in } \\
\text { Critically III Elderly Patients }\end{array}$ \\
\hline $\begin{array}{l}\text { Central nervous } \\
\text { system }\end{array}$ & $\begin{array}{l}\downarrow \text { Brain mass } \\
\downarrow \text { Cerebral blood flow } \\
\downarrow \text { Neuronal Density } \\
\downarrow \text { Receptor Responsiveness } \\
\downarrow \text { Overall processing speed } \\
\text { Hormonal Changes }\end{array}$ & $\begin{array}{l}\text { Cerebral irritation } \\
\text { Alterations in the Blood brain } \\
\text { barrier } \\
\text { Fluctuation in mental status } \\
\text { Fluctuation in the sleep wake } \\
\text { cycle }\end{array}$ & $\begin{array}{l}\text { Overly exaggerated CNS } \\
\text { response } \\
\text { Neuromuscular blockade is } \\
\text { more intense } \\
\text { Reversal by neuromuscular } \\
\text { blockade antagonists is more } \\
\text { difficult } \\
\uparrow \text { Risk for ADEs and delirium }\end{array}$ & $\begin{array}{l}\text { Benzodiazepines } \\
\text { Opioids } \\
\text { Barbiturates } \\
\text { Neuromuscular blockers }\end{array}$ \\
\hline $\begin{array}{l}\text { Cardiovascular } \\
\text { System }\end{array}$ & $\begin{array}{l}\downarrow \text { Number of myocytes } \\
\uparrow \text { Myocardial collagen } \\
\downarrow \text { Vessel elasticity and distendability } \\
\downarrow \text { Ejection fraction } \\
\text { Desensitation of Beta-adrenergic } \\
\text { receptors }\end{array}$ & $\begin{array}{l}\uparrow \downarrow \text { Blood pressure } \\
\uparrow \% \text { of CO will go to essential } \\
\text { organs }\end{array}$ & $\begin{array}{l}\uparrow \quad \text { Sensitivity to negative } \\
\text { inotropy and vasodilatory } \\
\text { effects } \\
\uparrow \text { Drug concentration in heart } \\
\text { and brain }\end{array}$ & $\begin{array}{l}\text { Dopamine } \\
\text { Epinephrine } \\
\text { Norepinephrine } \\
\text { Dobutamine } \\
\text { Vasopressin } \\
\text { Phenylephrine }\end{array}$ \\
\hline Respiratory system & $\begin{array}{l}\downarrow \text { Respiratory Reserve } \\
\downarrow \text { Chest wall compliance } \\
\downarrow \text { Maximum inspiratory and expiratory } \\
\text { force } \\
\downarrow \text { Elasticity of airways }\end{array}$ & $\uparrow \mathrm{PaCO}_{2}$ & $\begin{array}{l}\text { Aspiration pneumonia } \\
\text { Higher risk of respiratory } \\
\text { failure } \\
\text { Prolonged time to wean from } \\
\text { ventilator }\end{array}$ & $\begin{array}{l}\text { Benzodiazepines } \\
\text { Sedative-Hypnotics } \\
\text { Anticholinergics } \\
\text { Proton pump inhibitors }\end{array}$ \\
\hline Immune System & $\begin{array}{l}\downarrow T \text { cell responsiveness } \\
\downarrow B \text { cell and antibody responsiveness }\end{array}$ & $\begin{array}{l}\uparrow \text { Release of proinflammatory } \\
\text { cytokines }\end{array}$ & $\begin{array}{l}\uparrow \text { Risk for developing } \\
\text { infections }\end{array}$ & \\
\hline
\end{tabular}

Table 3: Combined Effects of Pharmacodynamic Changes in Critically Ill Older [22].

\section{Central nervous system}

Medications that affect the CNS and are commonly used in the ICU can lead to an overly exaggerated CNS response. Older adults are more sensitive to certain benzodiazepines, anesthetics, and opioids [40]. In addition, an overstated response to certain lipid-soluble drugs is frequently observed due to the ability to cross the blood-brain-barrier [41]. After intravenous midazolam is given, the half-maximum effective concentration (EC50) is reduced by $50 \%$ in older adults [42]. Older adults show an approximate $50 \%$ increase in sensitivity to certain opioids such as alfentanil, fentanyl, and remifentanil and therefore, require dosing adjustments [43,44]. Specifically, older patients, especially those greater than 80 years of age, require half of the fentanyl or alfentanil dose compared to younger patients [8].

Adverse drug events may occur due to changes in enzyme and neurotransmitter activity as well as specific receptor sites. Frail older adults greater than 65 years of age reported more sedation after a 10 mg intravenous dose of metoclopramide which seemed to reflective of associated PD changes in specific receptor or target sites [45]. Functional activity of cerebrovascular p-glycoprotein (PgP) efflux pumps in the blood-brain barrier is reduced with aging. These pumps actively transport some drugs out of the brain, so the CNS may be exposed to possible instances of drug toxicity even in the presence of low serum concentrations [40]. In addition, critical illness can cause multiple mechanisms of injury to the brain, including breakdown of the blood-brain barrier (BBB) [46]. Examples of $\operatorname{PgP}$ substrates, inhibitors, and inducers commonly used in the ICU include ondansetron, conivaptan, and dexamethasone, respectively. Dopamine depletion in extrapyradimal centers of the brain make older patients more susceptible to antipsychotic-induced reversible extrapyramidal adverse effects such as akathesia, dystonia, and pseudoparkinsonism compared with younger patients [41,47]. This is a significant consideration since dopamine D2 antagonist antipsychotic drugs are widely used to treat agitation associated with dementia in older adults as well as delirium in critically ill older adults.

\section{Cardiovascular system}

Cardiac disease is the most common comorbid condition in the elderly [48]. Older stroke patients can exhibit disruptions in the autonomic nervous system that lead to the decreased ability of regulatory processes to maintain blood pressure and heart rate [49]. In traumatic injury with major blood loss, elderly patients have poor compensatory mechanisms due to limited reserve as well as diastolic and kidney dysfunction [50]. In addition, age is a risk factor for QT interval prolongation [51]. Several agents used in critically ill patients can prolong the QT interval and induce life threatening arrhythmias, such as haloperidol, erythromycin, and moxifloxacin [52]. Intravenous haloperidol was given to manage severe agitation in 14 critically ill older patients, and in every case but one, the dose far exceeded $2 \mathrm{mg}$ necessary to produce an antipsychotic effect [53]. Critical care clinicians are using haloperidol for the sedative effects which occurs at doses greater than $2 \mathrm{mg}$, and this produced complications in 9 patients including torsades de pointes, ventricular fibrillation, and sudden cardiac death. Therefore, intravenous administration of these drugs in elderly critically ill patients should be closely monitored. 


\section{Respiratory system}

Deterioration in pulmonary function can make older adults more susceptible to complications, especially if patients are critically ill and require mechanical ventilation. Evidence suggests that chronic disease, not age, plays the most essential role in determining outcome in older adults who have experienced respiratory failure [54]. Long-acting benzodiazepines, opioids, sedative hypnotics and nonselective betaadrenergic antagonists may increase respiratory depression and the risk of aspiration pneumonia, especially in patients with preexisting pulmonary conditions such as chronic obstructive pulmonary disease (COPD). Sedative hypnotics should only be used on an as needed basis. Bolus doses versus continuous intravenous infusions of longacting medications should be considered.

\section{Immune system}

Immunocompetence in the elderly diminishes with age and altered immune system response makes diagnosis and monitoring difficult. Nursing home admission, recent hospitalization, or previous treatment for multidrug resistant organisms (MDRs) are important considerations when evaluating potential antimicrobial options. Elderly patients are more likely to have a previous ICU admission and comorbid conditions which lead to higher antimicrobial resistance and fewer options for treatment [55]. Older patients may not present with normal signs and symptoms of infection such as increased white blood cell counts and may only experience fever. Additionally, patients with no cognitive impairment before hospital admission may present with nonspecific signs such as altered mental status. Changes in cognitive function may be difficult to detect when frequent changes in care setting occur and acute cognitive decline should not be assumed to be due to underlying dementia. Clinicians should evaluate for possible sources of infection when patients present with a sudden onset of cognitive decline since typical signs and symptoms of infection may be absent in older adults.

Immunosenescence, defined as changes in the immune system associated with age, and comorbidities predispose older, more critically ill, adults to additional challenges of prescribing antimicrobials. Suboptimal therapeutic efficacy is a potential result when initiating or titrating antimicrobial doses. In general, medications that exhibit concentration-dependent killing (fluoroquinolones, aminoglycosides, metronidazole, and daptomycin) have improved bacteriocidal activity with increased serum concentrations. Therefore, peak serum concentration is more closely related to efficacy. Initiation with low doses of medications in older adults is a common recommendation, but aggressive antimicrobial dosing regimens should be considered for life-threatening infections while balancing concerns such as comorbidities, limited functional reserve, and immunosenescence [56]. This approach is essential to achieve optimal pharmacodynamics and clinical outcomes, especially in critically ill older adults who are more susceptible to increased antimicrobial resistance.

\section{General principles of pharmacotherapy for older critically ill patients}

1. Conservative dosing and more frequent follow-up may be warranted for patients taking newer high-risk medications that have not been fully evaluated in this patient population (eg, new oral anticoagulants).
2. Intermittent dosing, rather than continuous infusions, of opioids, neuromuscular junction blockers, and sedatives may be adequate.

3. Reduced daily doses of opioids, sedatives, neuromuscular junction blockers, and antipsychotics should also be considered.

4. All preoperative medications should be reviewed for appropriateness and PIMs should be stopped in older postoperative patients admitted to the ICU.

5. Dosing frequency based on drug levels for antibiotics, such as vancomycin and aminoglycosides, may be needed initially in the postoperative older patient with baseline renal dysfunction and reduced urine output.

6. Medication reconciliation upon discharge from the ICU is essential to reduce medication errors and total drug exposure in critically ill older adults.

\section{Conclusion}

Medical advances have lengthened the life expectancy which has led to older adults occupying more ICU beds. Medication management in critically ill older adults is often complex and requires multiple dosage adjustments. There is limited data regarding treatment recommendations. More clinical trials are needed to identify optimal pharmacotherapy treatment and dosing regimens for older adults battling critical illness. Moreover, medication reconciliation on admission to and transfer from the ICU is an important step to reduce the drug burden. Specifically, medications that may contribute to cognitive decline should be reevaluated. Monitoring for ADEs, such as nephrotoxicity and neurotoxicity, is paramount in critically ill elderly adults with altered $\mathrm{PK} / \mathrm{PD}$ characteristics. As the patient improves, always reassess the need for certain medications such as H2RAs, opioids and sedative medications. Given that ICU delirium is associated with higher mortality, further prevention, detection, and treatment efforts are warranted.

\section{References}

1. Lowy, F (2011) Inappropriate medications commonly prescribed to the elderly in the ICU.

2. http://www.census.gov.proxy.library.vcu.edu/population/socdemo/ statbriefs/agebrief.html.

3. Stewart RB, Cooper JW (1994) Polypharmacy in the aged. Practical solutions. Drugs Aging 4: 449-461.

4. Cho S, Lau SW, Tandon V, Kumi K, Pfuma E, et al. (2011) Geriatric drug evaluation: where are we now and where should we be in the future? Arch Intern Med 171: 937-940.

5. Oresanya LB, Lyons WL, Finlayson E (2014) Preoperative assessment of the older patient: a narrative review. JAMA 311:2110-2120.

6. Watts G (2012) Why the exclusion of older people from clinical research must stop. BMJ 344: e3445.

7. Mutasingwa DR, Ge H, Upshur RE (2011) How applicable are clinical practice guidelines to elderly patients with comorbidities? Can Fam Physician 57: e253-262.

8. Shafer SL (2000) The pharmacology of anesthetic drugs in elderly patients. Anesthesiol Clin North America 18: 1-29, v.

9. Murphy CE, Stevens AM, Ferrentino N, Crookes BA, Hebert JC, et al. (2008) Frequency of inappropriate continuation of acid suppressive therapy after discharge in patients who began therapy in the surgical intensive care unit. Pharmacotherapy 28: 968-976.

10. Castelino RL, Hilmer SN, Bajorek BV, Nishtala P, Chen TF (2010) Drug Burden Index and potentially inappropriate medications in community- 
dwelling older people: the impact of Home Medicines Review. Drugs Aging 27: 135-148.

11. Beers MH, Ouslander JG, Rollingher I, Reuben DB, Brooks J, et al. (1991) Explicit criteria for determining inappropriate medication use in nursing home residents. UCLA Division of Geriatric Medicine. Arch Intern Med 151: $1825-1832$

12. Hamilton H, Gallagher P, Ryan C, Byrne S, O'Mahony D (2011) Potentially inappropriate medications defined by STOPP criteria and the risk of adverse drug events in older hospitalized patients. Arch Intern Med 171: 1013-1019.

13. American Geriatrics Society 2012 Beers Criteria Update Expert Panel (2012) American geriatrics society updated beers criteria for potentially inappropriate medication use in older adults. J Am Geriatr Soc 60: 616-631.

14. Hilmer SN, Mager DE, Simonsick EM, Cao Y, Ling SM, et al. (2007) A drug burden index to define the functional burden of medications in older people. Arch Intern Med 167: 781-787.

15. Morandi A, Vasilevskis EE, Pandharipande PP, Girard TD, Solberg LM, et al. (2011) Inappropriate medications in elderly ICU survivors: where to intervene? Arch Intern Med 171: 1032-1034.

16. Leslie DL, Marcantonio ER, Zhang Y, Leo-Summers L, Inouye SK (2008) One-year health care costs associated with delirium in the elderly population. Arch Intern Med 168: 27-32.

17. Inouye SK (2006) Delirium in older persons. N Engl J Med 354: 1157-1165.

18. Clegg A, Young JB (2011) Which medications to avoid in people at risk of delirium: a systematic review. Age Ageing 40: 23-29.

19. Pisani MA, Redlich C, McNicoll L, Ely EW, Inouye SK (2003) Underrecognition of preexisting cognitive impairment by physicians in older ICU patients. Chest 124: 2267-2274.

20. Fraser GL, Prato BS, Riker RR, Berthiaume D, Wilkins ML (2000) Frequency, severity, and treatment of agitation in young versus elderly patients in the ICU. Pharmacotherapy 20: 75-82.

21. Slattum PW, Venitz J (2004) Clinical pharmacokinetics in the elderly. In: Handbook of anticancer pharmacokinetics and pharmacodynamics. Edited by Figg WD, McLeod HL. Totowa: Humana Press Inc.

22. Boucher BA, Wood GC, Swanson JM (2006) Pharmacokinetic changes in critical illness. Crit Care Clin 22: 255-27, vi.

23. Moureau NL (2008) Tips for inserting an I.V. device in an older adult. Nursing 38: 12 .

24. Turnheim K (2003) When drug therapy gets old: pharmacokinetics and pharmacodynamics in the elderly. Exp Gerontol 38: 843-853

25. Krishnan V, Murray P (2003) Pharmacologic issues in the critically ill. Clin Chest Med 24: 671-688.

26. Cusack BJ (2004) Pharmacokinetics in older persons. Am J Geriatr Pharmacother 2: 274-302.

27. Rivera R, Antognini JF (2009) Perioperative drug therapy in elderly patients. Anesthesiology 110: 1176-1181.

28. Papadopoulos J, Smithburger PL (2012) Common drug interactions leading to adverse drug events in the ICU: Management and pharmacokinetic considerations. In: Drug-induced complications in the critically ill patient: A guide for recognition and treatment. Edited by Papadopoulous J, Cooper BE, Kane-Gill SL, Corbett SM, Barletta JF. Mount Prospect: Society of Critical Care Medicine 1: 401-412.

29. Rockwood K, Song X, MacKnight C, Bergman H, Hogan DB, et al. (2005) A global clinical measure of fitness and frailty in elderly people. CMAJ 173: 489-495

30. McDermid RC, Stelfox HT, Bagshaw SM (2011) Frailty in the critically ill: a novel concept. Crit Care 15: 301

31. Hutchison LC (2010) Biomedical principles of aging. In: Fundamentals of geriatric pharmacotherapy: An evidenced-based approach. Bethesda: American Society of Health-System Pharmacists.

32. Marik PE (2006) Management of the critically ill geriatric patient. Crit Care Med 34: S176-182.
33. Kohli HS, Bhaskaran MC, Muthukumar T, Thennarasu K, Sud K, et al. (2000) Treatment-related acute renal failure in the elderly: a hospitalbased prospective study. Nephrol Dial Transplant 15: 212-217.

34. Spriet I, Goyens J, Meersseman W, Wilmer A, Willems L, et al. (2007) Interaction between valproate and meropenem: a retrospective study. Ann Pharmacother 41: 1130-1136.

35. Stahlmann R, Lode H (2010) Safety considerations of fluoroquinolones in the elderly: an update. Drugs Aging 27: 193-209.

36. Brummel NE, Girard TD (2013) Preventing delirium in the intensive care unit. Crit Care Clin 29: 51-65.

37. Cantú TG, Korek JS (1991) Central nervous system reactions to histamine-2 receptor blockers. Ann Intern Med 114: 1027-1034.

38. Slugg PH, Haug MT 3rd, Pippenger CE (1992) Ranitidine pharmacokinetics and adverse central nervous system reactions. Arch Intern Med 152: 2325-2329.

39. Klotz U (2007) Antiarrhythmics: elimination and dosage considerations in hepatic impairment. Clin Pharmacokinet 46: 985-996.

40. Bowie MW, Slattum PW (2007) Pharmacodynamics in older adults: a review. Am J Geriatr Pharmacother 5: 263-303.

41. Lamy PP (1991) Physiological changes due to age. Pharmacodynamic changes of drug action and implications for therapy. Drugs Aging 1: 385-404.

42. Albrecht S, Ihmsen H, Hering W, Geisslinger G, Dingemanse J, et al. (1999) The effect of age on the pharmacokinetics and pharmacodynamics of midazolam. Clin Pharmacol Ther 65: 630-639.

43. Scott JC, Stanski DR (1987) Decreased fentanyl and alfentanil dose requirements with age. A simultaneous pharmacokinetic and pharmacodynamic evaluation. J Pharmacol Exp Ther 240: 159-166.

44. Minto CF, Schnider TW, Egan TD, Youngs E, Lemmens HJ, et al. (1997) Influence of age and gender on the pharmacokinetics and pharmacodynamics of remifentanil. I. Model development. Anesthesiology 86: 10-23.

45. Wynne HA, Yelland C, Cope LH, Boddy A, Woodhouse KW, et al (1993) The association of age and frailty with the pharmacokinetics and pharmacodynamics of metoclopramide. Age Ageing 22: 354-359.

46. Morandi A, Hughes CG, Girard TD, McAuley DF, Ely EW, et al. (2011) Statins and brain dysfunction: a hypothesis to reduce the burden of cognitive impairment in patients who are critically ill. Chest 140 580-585.

47. Saltz BL, Robinson DG, Woerner MG (2004) Recognizing and managing antipsychotic drug treatment side effects in the elderly. Prim Care Companion J Clin Psychiatry 6: 14-19.

48. Rosenthal RA, Kavic SM (2004) Assessment and management of the geriatric patient. Crit Care Med 32: S92-105.

49. Panayiotou B, Reid J, Fotherby M, Crome P (1999) Orthostatic haemodynamic responses in acute stroke. Postgrad Med J 75: 213-218.

50. Lewis MC, Abouelenin K, Paniagua M (2007) Geriatric trauma: special considerations in the anesthetic management of the injured elderly patient. Anesthesiol Clin 25: 75-90.

51. Vieweg WV, Wood MA, Fernandez A, Beatty-Brooks M, Hasnain M, et al. (2009) Proarrhythmic risk with antipsychotic and antidepressant drugs: implications in the elderly. Drugs Aging 26: 997-1012.

52. Li EC, Esterly JS, Pohl S, Scott SD, McBride BF (2010) Drug-induced QTinterval prolongation: considerations for clinicians. Pharmacotherapy 30 684-701.

53. Kapur S, Seeman P (2001) Does fast dissociation from the dopamine d(2) receptor explain the action of atypical antipsychotics?: A new hypothesis. Am J Psychiatry 158: 360-369.

54. Sevransky JE, Haponik EF (2003) Respiratory failure in elderly patients. Clin Geriatr Med 19: 205-224.

55. Wang H, Liu N, Yin M, Han H, Yue J, et al. (2014) The epidemiology, antifungal use and risk factors of death in elderly patients with candidemia: a multicentre retrospective study. BMC Infect Dis 14: 609.

56. Faulkner CM, Cox HL, Williamson JC (2005) Unique aspects of antimicrobial use in older adults. Clin Infect Dis 40: 997-1004. 